\title{
BOOST CHOPPER DUA FASA DENGAN FILTER LC KELUARAN
}

\author{
Achmad Mudawari \\ Jurusan Teknik Konversi Energi- Politeknik Negeri Bandung \\ Jl. Gegerkalong Hilir, Ds. Ciwaruga - Bandung 40551 \\ Mail: mudawari@yahoo.com
}

\begin{abstract}
Abstrak
Penelitian ini mengusulkan satu konsep baru dalam teknologi boost konverter DC ke DC tak terisolasi yang dilengkapi dengan fiter LC. Topologi ini mempunyai riak keluaran yang rendah dan tegangan keluaran yang relative stabil. Untuk dapat meghasilkan converter dengan riak yang rendah maka besarnya filter ini dioptimasi berdasarkan criteria energi minimum yang tersimpan pada filter
\end{abstract}

Kata kunci : Boost chopper, riak keluaran, LC output filter

\section{PENDAHULUAN}

DC chopper banyak digunakan sebagai power suply dan salah satu kriteria yang menyatakan kualitas power suply adalah riak yang kecil. Ada beberapa macam topologi DC Chopper yaitu buck chopper, boost chopper, buck andd boost chopper. Pada tulisan ini dibahas boost DC chopper duayang dilengkapi dengan filter LC keluaran.

\section{Topologi boost chopper dua fasa}

Topologi boost chopper dua fasa diperlihatkan pada gambar 1

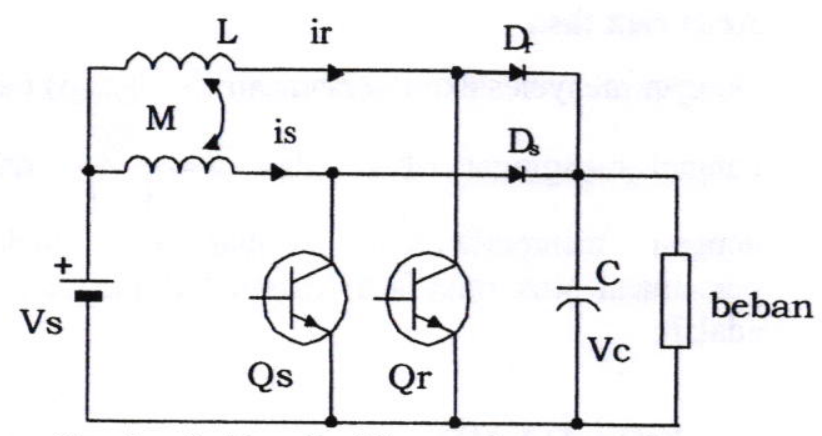

Gambar 1. Topologi boost chopper 2 fasa

Kerja rangkaian dapat dibagi atas dua mode kerja, yaitu mode pertama ketika saklar $\mathrm{Q}_{\mathrm{r}}$ on (bersamaan dengan $\mathrm{Q}_{s}$ off) serta mode kedua ketika $\mathrm{Q}_{\mathrm{r}}$ off (bersamaan dengan $\mathrm{Q}_{\mathrm{s}}$ on).
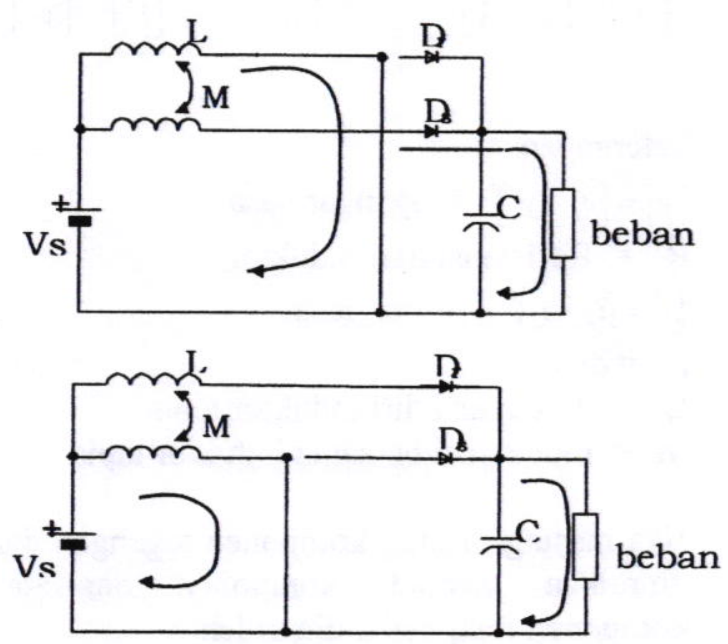

Gambar 2. Rangkaian ekivalen

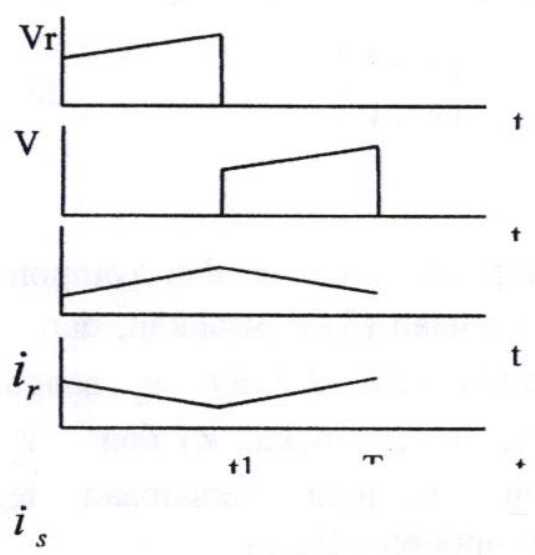

Gambar 3. Gelombang tegangan dan arus fasa 
Dengan memperhatikan Gb.1 sampai dengan gambar.3 dapat dilihat bahwa boost chopper dua fasa konduksi saklarnya dapat terjadi

a. Qr konduksi selama t1, Qs tidak konduksi selama T-t1

b. Qr tidak konduksi selama t1, Qs konduksi selama T-tl

Tegangan fasa yang dirasakan masing-masing fasa pada chopper tersebut akan dipengaruhi oleh dua kondisi diatas.

\section{Persamaan tegangan}

Dengan memperhatikan gambar 1. sampai gambar 3. maka persamaan tengangan fasa dapat dituliskan

$$
\begin{aligned}
& {[V]=[R][i]+p \cdot[L][i]+[V c]} \\
& {\left[\begin{array}{l}
v_{r} \\
v_{s}
\end{array}\right]=\left[\begin{array}{ll}
R & 0 \\
0 & R
\end{array}\right]\left[\begin{array}{l}
i_{r} \\
i_{s}
\end{array}\right]+p \cdot\left[\begin{array}{cc}
L & M \\
M & L
\end{array}\right]\left[\begin{array}{l}
i_{r} \\
i_{s}
\end{array}\right]+\left[\begin{array}{l}
v_{c} \\
v_{c}
\end{array}\right]}
\end{aligned}
$$

\section{keterangan}

$[v]=\left[\begin{array}{ll}v_{r} & v_{s}\end{array}\right]^{t}=$ tegangan fasa

$\mathbf{R}=$ Resistansi dari induktor

$[i]=\left[\begin{array}{ll}i_{r} & i_{s}\end{array}\right]^{t}=$ arus fasa

$\mathrm{p}=\mathrm{d} / \mathrm{dt}$

$\mathrm{L}=$ Induktansi diri induktor tapis

$\mathbf{M}=$ Induktansi bersama induktor tapis

Jika masing-masing komponen tegangan dan arus diuraikan menjadi komponen rata-rata dan komponen riak, maka diperoleh

$$
\begin{aligned}
{\left[\begin{array}{l}
\bar{v}_{r}+\tilde{v}_{r} \\
\bar{v}_{s}+\tilde{v}_{s}
\end{array}\right]=} & {\left[\begin{array}{ll}
R & 0 \\
0 & R
\end{array}\right]\left[\begin{array}{l}
\bar{i}_{r}+\tilde{i}_{r} \\
\bar{i}_{s}+\tilde{i}_{s}
\end{array}\right]+p \cdot\left[\begin{array}{cc}
L & M \\
M & L
\end{array}\right]\left[\begin{array}{l}
\bar{i}_{r}+\tilde{i}_{r} \\
\bar{i}_{s}+\tilde{i}_{s}
\end{array}\right] } \\
& +\left[\begin{array}{l}
\bar{v}_{c}+\tilde{v}_{c} \\
\bar{v}_{c}+\tilde{v}_{c}
\end{array}\right]
\end{aligned}
$$

Jika komponen rata-rata dan komponen riak pada persamaan (3) dipisahkan, dan $p \bar{i}=0$ dan apabila nilai $R . \tilde{i}$ dan $\widetilde{v}_{c}$ sangat kecil dibanding $p . \tilde{i}$, maka $R . \tilde{i}$ dan $\tilde{v}_{c}$ dapat diabaikan sehingga persamaan tegangan untuk komponen riaknya

$$
\left[\begin{array}{c}
\tilde{v}_{r} \\
\tilde{v}_{s}
\end{array}\right]=p \cdot\left[\begin{array}{cc}
L & M \\
M & L
\end{array}\right]\left[\begin{array}{c}
\tilde{i}_{r} \\
\tilde{i}_{s}
\end{array}\right]
$$

$$
\begin{aligned}
& p \cdot\left[\begin{array}{l}
\tilde{i}_{r} \\
\tilde{i}_{s}
\end{array}\right]=\left[\begin{array}{cc}
L & M \\
M & L
\end{array}\right]^{-1}\left[\begin{array}{l}
\tilde{v}_{r} \\
\tilde{v}_{s}
\end{array}\right] \\
& {\left[\begin{array}{l}
\tilde{v}_{r} \\
\tilde{v}_{s}
\end{array}\right]=\left[\begin{array}{l}
v_{r} \\
v_{s}
\end{array}\right]-\left[\begin{array}{l}
\bar{v}_{r} \\
\bar{v}_{s}
\end{array}\right]}
\end{aligned}
$$

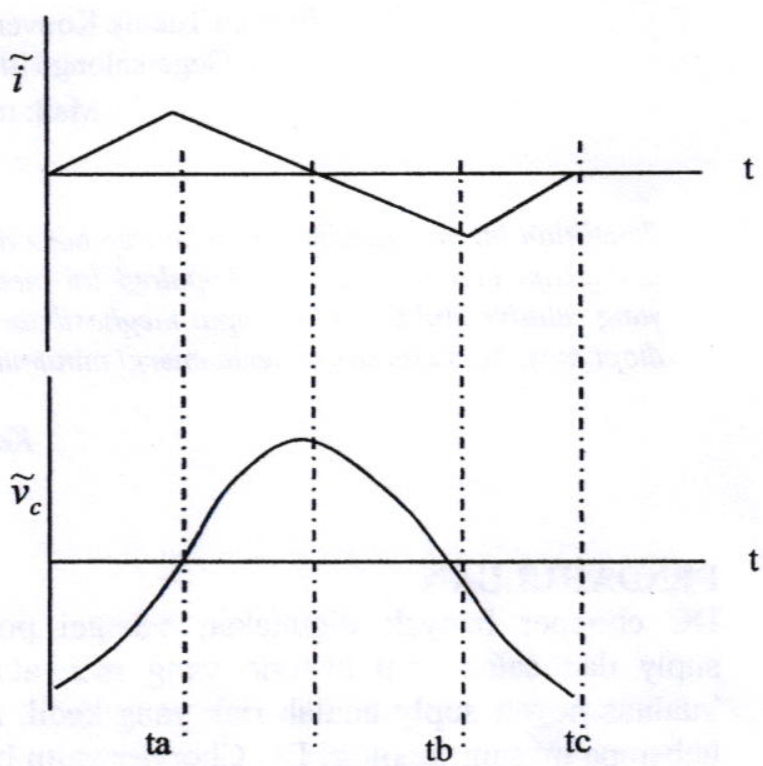

keterangan:

$$
\text { ta }=\mathrm{DT} / 2 \quad \mathrm{tb}=(2-\mathrm{D}) \mathrm{T} / 2 \quad \mathrm{tc}=\mathrm{T}
$$

Gambar 4. Gelombang arus riak fasa

\section{Arus riak fasa}

Dengan menyelesaikan persamaan (5) dan (6) dan dengan mengingat $\mathrm{M}=\mathrm{kL}$ dan $\vec{v}=\frac{V_{s}}{1-D}$ dan dengan memperhatikan gambar (4), maka persamaan arus riak fasa (dalam hal ini fasa $r$ ) adalah:

$$
\tilde{i}=\frac{V s(1-D+k D)}{L\left(1-k^{2}\right)} t \quad 0<\mathrm{t}<\mathrm{DT} / 2
$$

$$
\widetilde{i}=-\frac{V s(1-D+k D)}{L\left(1-k^{2}\right)} t+\frac{V_{s}(D+k-k D)}{2 f L\left(1-k^{2}\right)}
$$

$\mathrm{DT} / 2<\mathrm{t}<\mathrm{T} / 2(2-\mathrm{D})$

$\widetilde{i}=-\frac{V_{s}(D-k D)}{L\left(1-k^{2}\right)} t+\frac{V_{s}(D+k-k D)}{2 f L\left(1-k^{2}\right)}$

$\mathrm{T} / 2(1-\mathrm{D})<\mathrm{t}<\mathrm{T} / 2(1+\mathrm{D})$ 


$$
\begin{array}{lr}
\tilde{i}=-\frac{V_{s}(D-k D)}{L\left(1-k^{2}\right)} t+\frac{V_{s}(D-2 k D)}{2 f L\left(1-k^{2}\right)} & i_{L}=i_{r}+i_{s} \\
\mathrm{~T} / 2(1+\mathrm{D})<\mathrm{t}<\mathrm{T} / 2(2-\mathrm{D}) & \widetilde{i}_{L}=\widetilde{i}_{r}+\widetilde{i}_{s}
\end{array}
$$

$$
\widetilde{i}=\frac{V_{s}(1-D+k D)}{L\left(1-k^{2}\right)} t+\frac{V_{s}(-1+D-k D)}{f L\left(1-k^{2}\right)}
$$

$\mathrm{T} / 2(2-\mathrm{D})<\mathrm{t}<\mathrm{T} / 2$

\section{Arus riak effektif}

Nilai effektif arus riak fasa dapat dicari dengan memasukkan persamaan (7) sampai dengan (11) ke persamaan (12).

$$
\tilde{i}_{r(m s)}=\left(\frac{1}{T} \int\left(\widetilde{i_{r}}\right)^{2} d t\right)^{1 / 2}
$$

diperoleh

$$
\tilde{i}_{r m s}=\frac{v_{s} \cdot N}{f L\left(1-k^{2}\right)}
$$

dimana

$\left.N=\left(\begin{array}{l}2 D^{2}-4 D^{3}+2 D^{4}+2 k D^{2}-4 k D^{4}+2 k^{2} D^{2} \\ +2 k^{2} D^{3}+2 k^{2} D^{4}\end{array}\right) / 24\right)^{1 / 2}$

\section{Tegangan riak kapasitor}

Bentuk gelombang keluaran dari chopper masih mengandung riak, dan oleh karena itu diperlukan tapis untuk mereduksi riak pada sisi keluaranya.

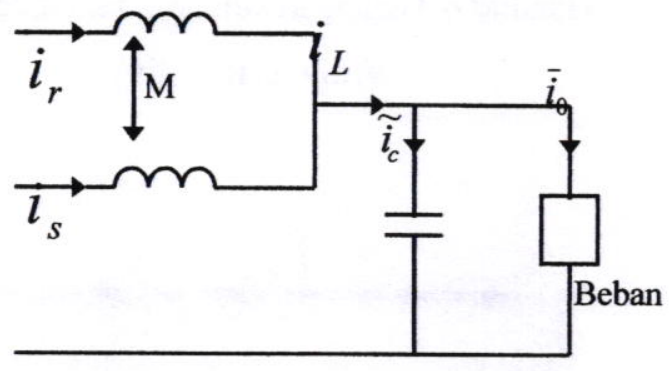

Gambar 5. arus riak total

Dalam merencanakan suatu tapis diharapkan arus yang mengandung riak akan masuk ke kapasitor dan arus rata-ratanya sebagai keluaran. Pada gambar (4) ditunjukan bagaimana arus total induktor berasal dan bercabang pada kapasitor tapis dan sebagai keluaran.

Arus keluaran

Diperoleh

$\widetilde{i_{L}}=\frac{V_{s}(1-2 D)}{L(1+k)} t$

$0<\mathrm{t}<\mathrm{DT} / 2$

$\widetilde{i}_{L}=\frac{2 V_{s} D}{L(1+k)} t+\frac{V_{s} D}{2 f L(1+k)}$

$\mathrm{DT} / 2<\mathrm{t}<\mathrm{T} / 2(1-\mathrm{D})$

$\tilde{i}_{L}=\frac{V_{s}(1-2 D)}{L(1+k)} t+\frac{V_{s}(1-2 D)}{2 f L(1+k)}$

$\mathrm{T} / 2(1-\mathrm{D})<\mathrm{t}<\mathrm{T} / 2$

Untuk kapasitor tapis yang besar, maka komponen arus riak keluaran $\widetilde{i_{0}}$ akan sangat kecil jika dibanding dengan komponen arus riak total induktor $\widetilde{i_{L}}$ sehingga komponen riak yang masuk ke kapasitor $\tilde{i}_{c}$ akan sama dengan arus riak total induktor $\tilde{i}_{L}$. Arus inilah yang menyebabkan tegangan riak kapasitor.

$$
\widetilde{v}_{c}=\frac{1}{C} \int \tilde{i}, d t+X
$$

Dengan memasukkan persamaan (14) sampai (16) ke persamaan (17) pada masing-masing interval, diperoleh

$\tilde{v}_{c}=\frac{V_{s}(1-2 D)}{2 L C(1-k)} t+X_{1} \quad 0<\mathrm{t}<\mathrm{DT} / 2$

$\widetilde{v}_{c}=-\frac{V_{s} D}{L C(1-k)} t^{2}+\frac{V_{s} D}{2 f L C(1+k)} t+X_{2}$

$\mathrm{DT} / 2<\mathrm{t}<\mathrm{T} / 2(1-\mathrm{D})$

$\tilde{v}_{c}=\frac{V_{s}(1-2 D)}{L C(1+k)} t^{2}-\frac{V_{s}(1-D)}{2 f L C(1+k)} t+X_{3}$

$\mathrm{T} / 2(1-\mathrm{D})<\mathrm{t}<\mathrm{T} / 2$

$\mathrm{X}$ adalah konstanta integrasi yang besarnya 


$$
\begin{aligned}
& X 1=\frac{V_{s}\left(-D+3 D^{3}-2 D^{3}\right)}{24 f^{2} L C(1-k)} \\
& X 2=-\frac{V_{s}\left(D+2 D^{3}\right)}{24 f^{2} L C(1-k)} \\
& X 3=\frac{V_{s}\left(3-7 D+3 D^{2}-2 D^{3}\right)}{24 f^{2} L C(1+k)}
\end{aligned}
$$

Nilai effektif riak tegangan kapasitor adalah

$$
\tilde{v}_{c(r m s)}=\left(\frac{1}{T} \int\left(\tilde{v}_{c}\right)^{2} d t\right)^{1 / 2}
$$

Diperoleh

$$
\begin{gathered}
\widetilde{v}_{c(r m s)}=\frac{V_{s} S}{24 L C(1+k)} \\
S=\left(\frac{D^{3}-20 D^{4}+48 D^{5}-32 D^{6}}{5}\right)^{1 / 2}
\end{gathered}
$$

Untuk kondisi $1 / 2<D<1$ dapat dihitung dengan menggunakan cara yang sama

Energi yang tersimpan pada filter merupakan penjumlahan dari energi yang tersimpan pada masing-masing filter yaitu,

$$
W=\frac{1}{4} L(1+k)\left(\tilde{i}_{L}\right)^{2}+\frac{1}{2} C\left(\tilde{v}_{c}\right)^{2}
$$

Supaya $\mathrm{W}$ minimum maka,

$$
\frac{\partial W}{\partial L}=0
$$

Diperoleh

$$
\begin{aligned}
& L=\frac{V_{0}}{2 \sqrt{3} I_{0} f(1+k)}\left(\frac{S}{D \cdot R F}\right)^{1 / 2} \\
& R F=\frac{\widetilde{v}_{0}}{V_{0}}
\end{aligned}
$$

Besarnya filter kapasitor dapat dihitung dengan mensubstitusikan pers (24) ke pers.(22) sehingga diperoleh,

$$
C=\frac{I_{0}}{4 \sqrt{3} f V_{0}}\left(\frac{S}{D \cdot R F}\right)^{1 / 2}
$$

Persamaan (24) dan (25) merupakan masingmasing merupakan besarnya filter induktor dan filter kapasitor yang paling optimum. Namun demkian besarnya filter tersebut harus ditentukan bersamaan dengan riplle faktor (RF) yang dkehendaki.

\section{PENGUJIAN}

Untuk menguji konsep yang diusulkan, telah dibuat prototip dengan menggunakan saklar statik MOSFET. Parameter rangkaian adalah sebagai berikut :

- $\mathrm{V}_{\text {in }} \quad=12 \mathrm{~V}$

- $\mathrm{L} \quad=500 \mathrm{uH} / / 500 \mathrm{uH}$

- $\mathrm{C} \quad=47 \mathrm{uF}$

- $\mathrm{Q}_{1}, \mathrm{Q}_{2}=\mathrm{IRF} 640$

- $\mathrm{D}_{1}, \mathrm{D}_{2}=\mathrm{FR} 104$

- $\mathrm{f}_{\text {switching }}=24 \mathrm{kHz}$

\section{Profil Tegangan dan Arus}

Untuk mengetahu profil arus dan tegangan topologi yang diusulkan, beberapa gambar bentuk tegangan dan arus telah diambil sebagaimana diperlihatkan pada gambar 6 hingga 12 .

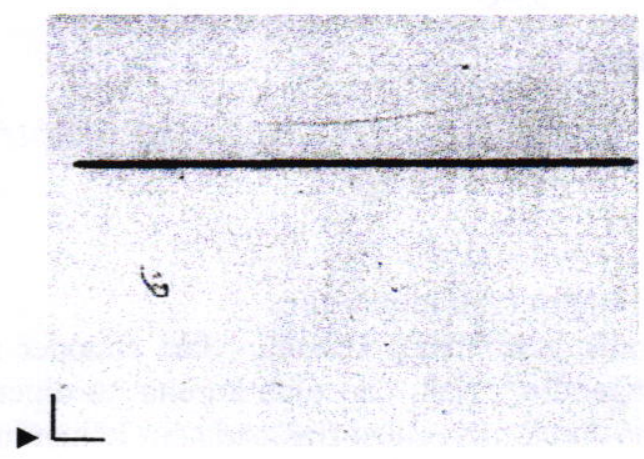

Gambar 6 Tegangan keluaran tanpa beban (5V/div, $0.1 \mathrm{~ms} /$ div)

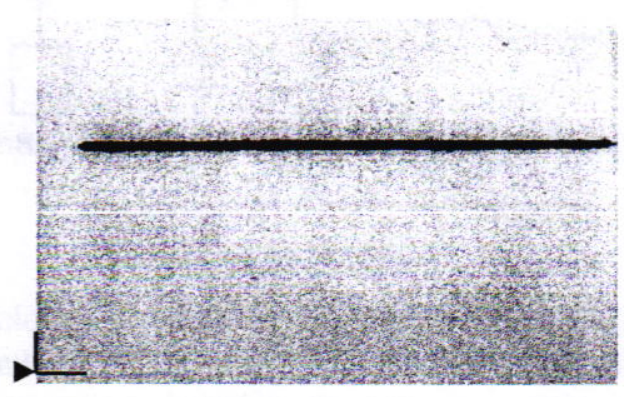

Gambar 7 Tegangan keluaran pada beban $492 \mathrm{~mA}$ (5V/div, $0.1 \mathrm{~ms} / \mathrm{div})$ 


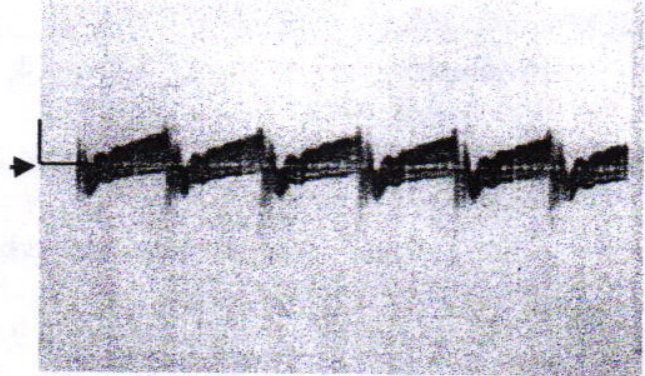

Gambar 8 Riak tegangan keluaran pada beban $492 \mathrm{~mA}$

pada tegangan rata-rata $22.2 \mathrm{~V} \quad(0.4 \mathrm{~V} / \mathrm{div}$, 0.5 us/div)

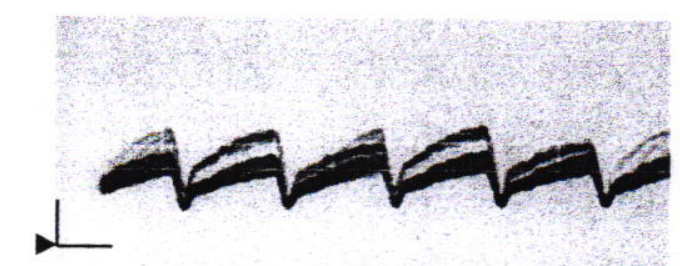

Gambar 9 Arus masukan pada beban $336 \mathrm{~mA}$ (0.5A/div, 5us/div)

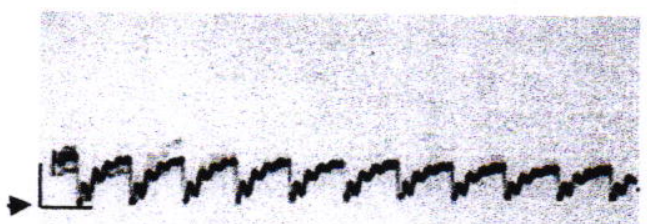

Gambar 10 Arus salah satu induktor pada beban $255 \mathrm{~mA}(0.5 \mathrm{~A} / \mathrm{div}, 10 \mathrm{us} / \mathrm{div})$

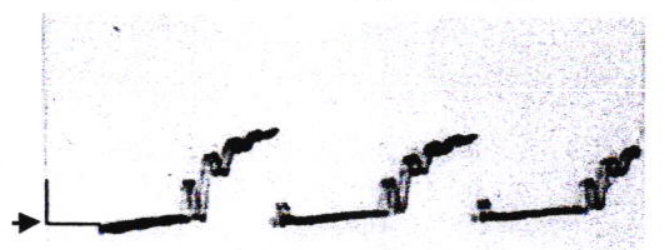

Gambar 11 Arus salahsatu transistor pada beban $255 \mathrm{~mA}(0.2 \mathrm{~A} / \mathrm{div}, 5 \mathrm{us} / \mathrm{div})$

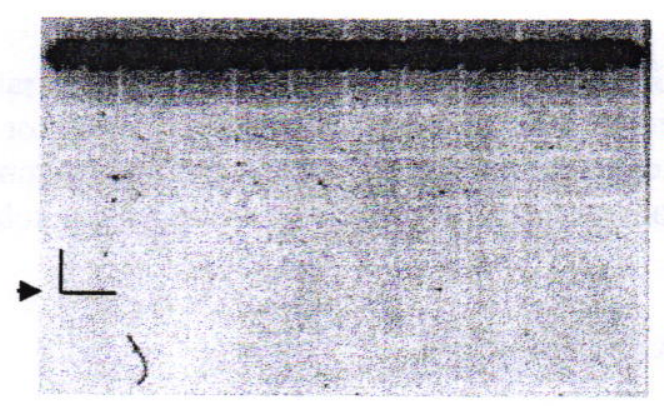

Gambar 12 Tegangan keluaran tanpa kapasitor filter keluaran pada beban $458 \mathrm{~mA}(5 \mathrm{~V} / \mathrm{div}$, 20us/div)

\section{Profil Pembebanan}

Profil pembebanan diperlihatkan pada tabel 1.

\begin{tabular}{|c|c|}
\hline $\begin{array}{c}\text { Arus keluaran } \\
(\mathbf{m A})\end{array}$ & $\begin{array}{c}\text { Tegangan } \\
\text { keluaran }(\mathbf{V})\end{array}$ \\
\hline 0 & 23.5 \\
\hline 271 & 22.7 \\
\hline 356 & 22.4 \\
\hline 522 & 22.0 \\
\hline 903 & 21.0 \\
\hline
\end{tabular}

Tabel 1 Profil pembebanan topologi boost chopper dua fasa

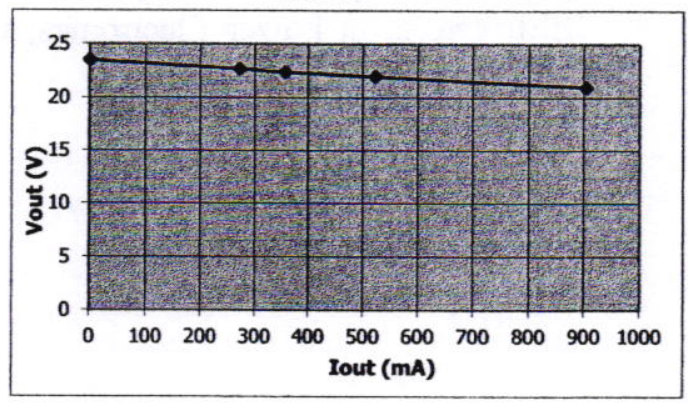

Gambar 13 Profil grafik pembebanan topologi boost chopper dua fasa

\section{ANALISIS}

Berdasarkan hasil percobaan, terlihat bahwa topologi yang diusulkan dapat bekerja dengan baik. Gambar 6 dan gambar 7 menunjukkan tegangan keluaran yang relatif konstan dan memiliki riak yang rendah yaitu sebesar $0.8 \mathrm{~V}_{\mathrm{pp}}$ walaupun dibebani hingga kisaran $0.5 \mathrm{~A}$. 
Gambar 12 menunjukkan tegangan keluaran yang tidak terlalu buruk walaupun kapasitor filter keluaran telah dilepas sedangkan gambar 13 memperlihatkan gambar profil tegangan keluaran

\section{KESIMPULAN}

Dari analisis dan percobaan, dapat disimpulkan sebagai berikut :

1. Topologi boost chopper yang diusulkan dapat diterapkan

2. Tegangan keluaran relatif stabil walaupun di bebani hingga sekitar $0,9 \mathrm{~A}$

3. Besarnya filter $\mathrm{L}$ dan $\mathrm{C}$ sangat dipengaruhi oleh seberapa besar riak keluaran yang diinginkan

\section{DAFTAR PUSTAKA}

Caballero and Barbi, A New Flyback-Current-Fed Push-Pull DC-DC Converter, IEEE Trans. on Power Electronics, vol.14, no 6, Nov. 1999

Dahono, Riyadi, Achmad Mudawari and Haroen, Output Ripple Analysis of Multiphase DCDC Converters, Proc. PEDS'99, July 1999, Hongkong

Huber and Jovanovic, Forward-Flyback Converter with Current-Doubler Rectifier:

Analysis, Design and Evaluation Results, IEEE Trans. on Power Electronics, vol.14, no.1, Jan. 1999
McMurray, Power Electronic Circuit Topology, Proceeding IEEE, vol. 76, no.4, pp.428437, April 1988

Nai and Wa, A Boost PWM Soft-Single-Switched Converter Average Switch Model for Small Signal and Transient Analysis, Proc. PEDS'99, July 1999, HK

Pfeffer, Yarema et.al., A Bipolar, High Precision, Low Ripple Power Supply, IEEE Trans. on Nuclear Science, vol. NS-30, no.4, Aug. 1983

Tanaka et.al., A New Control Method for Synchronous Rectifiers in Forward DC-DC Converters, Proc. IPEC Yokohama 1995 